\title{
O Milagre da Crioulização: Retrospectiva $^{1}$
}

Richard Price

\section{Resumo}

Neste ensaio o autor expande, desenvolve e atualiza idéias originalmente elaboradas no clássico $O$ nascimento da cultura a fro-americana, de 1973, no qual os autores propõem uma interpretação para o surgimento de formas culturais africano-americanas originais determinada pelo contexto das plantation societies. Ao mesmo tempo procura responder às críticas dirigidas contra o modelo desenvolvido nesse livro. As críticas podem ser associadas à "virada discursiva" prevalecente em muitos estudos contemporâneos, por um lado. Por outro, se ligam a uma interpretação engajada do passado africano-americano informada por teorias afrocêntricas ou críticas da supremacia branca e do eurocentrismo.

Palavras-chave: afro-americano, crioulização, negro, afrocentrismo, eurocentrismo, plantation societies.

\section{Abstract}

The miracle of blackening: retrospective

In this essay, the author develops ideas originally shown in 1973, in O Nascimento da Cultura Afro-Americana, in which the author proposes an interpretation of the original African-American cultural forms, determined by the plantation societies context. And it also tries to answer some critics directed to the model developed in this book. The critics might be associated to the prevailing "discursive turning-point" in recent studies. On the other hand, the critics can be related to an interpretation engaged in the African-American past, nurtured by the theories that believe in Africa as the center of all ("African-centrists") or 
by critics of the white supremacy and the theory that believes in Europe as the center of all ("European-centrists")

Keywords: African-American, blackening, Negro, Afrocentrism, Eurocentrism, plantation societies.

\section{Résumé}

\section{Le miracle du métissage. Retrospective}

Dans cet essai, l'auteur répend, développe et actualise des idées élaborées à l'origine dans le livre classique "La naissance de la culture afro-américaine", de 1973, dans lequel les auteurs proposent une interprétation pour le surgissement de formes culturelles afro-américaines originales qui sont déterminées par le contexte des "plantation societies". En même temps, il cherche à répondre aux critiques dirigées contre le modèle développé dans ce livre. D'un côté, les critiques peuvent être associées au "détournement discousif" qui prévaut dans de nombreuses études contemporaines; d'un autre côté, elles sont liées à une interprétation engagée du passé afro-américain informée par des théories afrocentriques ou par des critiques de la suprematie blanche et celle de l'eurocentrisme.

Mots-clés: afro-américain, métissage, Noir, afrocentrisme, eurocentrisme, plantation societies. 
$\mathrm{U}$ ns vinte anos atrás, quando éramos colegas na Universidade Johns Hopkins, Sid Mintz costumava me dizer que, quando abria a boca para dizer alguma coisa num seminário, era comum ter medo de que dela saíssem traças. Ao me aproximar da idade que ele tinha na época, começo a entender do que estava falando. Neste artigo, assumo a tarefa de expandir algumas idéias do ensaio que escrevi com Mintz em 1972 - que apresentamos em público em 1973, imprimimos em ofsete em 1976 e publicamos comercialmente, com um novo prefácio, como $O$ nascimento da cultura africano-americana, em 1992 (tradução em português, 2003). Esse prefácio discorreu sobre parte da história da acolhida dada àquele trabalho, observando que a publicação original

foi recebida, em algumas áreas, pelo que constituiu — para nós — uma hostilidade surpreendente, acompanhada pela acusação de que negava a existência de uma herança africana nas Américas. Muitas dessas reações pareceram originar-se num desejo de polarizar os estudos afro-americanistas numa posição puramente "pró" ou "contra", com respeito à preservação de formas culturais africanas. Por exemplo, Mervyn Alleyne chamou-nos de "teóricos da criação", acusando-nos de uma atenção exagerada para com a criatividade cultural dos africanos escravizados no Novo Mundo; no entanto, seu próprio livro chega a conclusões próximas das nossas. Daniel Crowley criticou duramente o livro de Sally e Richard Price, Afro-American arts of the Suriname rain forest [Artes afroamericanas da floresta tropical do Suriname], que desenvolve a abordagem conceitual num contexto histórico específico, e o acusou de "exagerar extravagantemente uma boa argumentação". Joey Dillard considerou os autores como "não [estando] completamente do lado dos anjos" e tendo argumentos "controvertidos, se não decididamente heréticos". (Mintz \& Price, 2003:7-8)

Nos últimos anos, desde que aquele ensaio atingiu um público maior, essas controvérsias se intensificaram. Na verdade, descubro-me agora (assim como a meu trabalho, incluindo, mas dificilmente limitando-se ao ensaio de $\mathrm{M} \& \mathrm{P}$ ) mais enredado do que nunca numa série de debates, às vezes ásperos. Minha intenção, neste artigo, é tentar definir algumas das questões, esclarecer o que 
está em jogo em termos teóricos e metodológicos e sugerir maneiras pelas quais alguns aspectos do "modelo de M\&P" poderiam ser usados com proveito na exploração contínua do passado africano-americano. ${ }^{2}$

Foi entre os historiadores da escravidão norte-americana que essas questões entraram recentemente num debate mais acalorado (talvez pelo fato de os historiadores norte-americanos da escravidão haverem chegado muito recentemente ao estudo do "processo"). Como agora ficou claro, muitas das obras canônicas sobre a escravidão e as comunidades de escravos nos Estados Unidos por exemplo, Blassingame (1972), Genovese (1974), Rawick (1972) - trataram essa "instituição peculiar" de modo predominantemente sincrônico, baseando suas interpretaçóes quase que exclusivamente no histórico oitocentista anterior à guerra, que é sedutoramente rico. Nos últimos anos, contudo, praticamente uma enxurrada de livros de história tem-se dedicado ao desenvolvimento da escravidão norte-americana, desigual e variável conforme a região, e boa parte do debate voltou-se para os aspectos mutáveis da vida cultural dos escravos. Os seguintes tipos de perguntas (antes antropológicas) vêm hoje sendo formulados, com freqüência cada vez maior, pelos historiadores norte-americanos: quão "etnicamente" homogêneos (ou heterogêneos) eram os africanos escravizados que chegaram a localidades específicas e quais foram as conseqüências culturais disso? Quais foram os processos pelos quais esses africanos tornaram-se africano-americanos? Com que rapidez e de que maneira os africanos transportados para as Américas como escravos, bem como seus descendentes africano-americanos, começaram a pensar e agir como membros de novas comunidades - isto é, quão rápida foi a crioulização? De que formas os africanos recém-chegados escolheram - e conseguiram - dar continuidade a determinados modos de pensar e de agir que vinham do Mundo Antigo? Como foi que os vários perfis demográficos e condiçôes sociais das plantations do Novo Mundo, em determinadas épocas e lugares, incentivaram ou inibiram esses processos? Até mesmo um exame superficial de obras tão discutidas como Many thousands gone, de Ira Berlin, Exchanging our country marks, de Michael Gomez, Slave counterpoint, de Philip Morgan, ou Africa and Africans in the making of the Atlantic world, 1400-1800, de John Thornton - todos publicados nos últimos anos - mostra a que ponto essas perguntas, subitamente, tornaram-se importantes e polêmicas para os que praticam a História norte-americana. 
Um segundo conjunto de questões - de interesse reconhecidamente menor para os historiadores propriamente ditos - veio à baila, de modo sumamente vigoroso, num ensaio do antropólogo jamaicano David Scott (1991), que sugere que os antropólogos dedicados ao estudo da afro-América devem desviar a atenção do esforço inútil, e talvez até moralmente suspeito, de expor, verificar ou corroborar "passados africano-americanos autênticos" ("o que realmente aconteceu”) e, em vez disso, concentrá-la em como os africano-americanos de várias partes do hemisfério contemplam seu passado e falam e agem em termos dele. ${ }^{3}$ Nosso foco, diz ele, deveria incidir sobre a "tradição" - por exemplo, os modos como os africano-americanos empregam a "África”, a "escravidão" ou "a Rota do Meio" "na construção narrativa de relações entre passados, presentes e futuros" (p. 278). "Que espaço", diz ele que deveríamos perguntar, "ocupam a África e a escravidão na economia política do discurso local?” (p. 279). Em suma, deveríamos concentrar-nos no "discurso" e nas realidades que ele cria, em vez de fazer vãs tentativas de reconstituir "eventos". Ao longo do ensaio, Scott usa o trabalho de Melville Herskovits e meu livro First-Time (1983a) como exemplos de duas etapas daquilo que vê como uma busca antropológica unitária. "Não admira", diz ele, que a antropologia africano-americana "manifeste uma profunda inclinação humanista para uma história das continuidades, e que abrace a tarefa convicta de demonstrar a integridade e a inalterabilidade do velho no novo e do passado no presente" (p. 262). E, nessa narrativa, "África" e "escravidão" constituem os pontos de referência. "Na economia discursiva ou narrativa dessa problemática antropológica, escravidão e 'Áfricà funcionam como termos praticamente intercambiáveis, ou, dito de outra maneira, a escravidão, na obra de Price, passa a exercer o mesmo trabalho retórico-conceitual que a África na obra de Herskovits" (p. 263). "Ambos", prossegue ele, "giram em torno de uma clara tentativa de relacionar as 'culturas' dos ex-africanos/ex-escravos com o que poderíamos chamar de um passado autêntico, ou seja, um passado antropologicamente identificável, etnologicamente recuperável e textualmente representável” (p. 263).

Seja qual for o incômodo de Scott diante dessa narrativamestra da continuidade e da ideologia que ele acredita ser-lhe subjacente, não parece haver dúvida de que os historiadores da escravidão, assim como os antropólogos afro-americanistas, em geral a têm endossado. Aliás, eu diria que essa é uma narrativa quintessencialmente norte-americana (estadunidense), proveniente, em par- 
te, das especificidades do racismo norte-americano, e não de uma especificidade estritamente antropológica.

Eu gostaria de distinguir e examinar duas versões rivais do que Scott entende por uma única narrativa-mestra, pois creio que persiste uma distância considerável e significativa entre a exposição dos passados de Saramaca feita pelos Herskovitses e a feita pelos Prices, ou entre a descrição do desenvolvimento da vida escrava, na América do Norte colonial, formulada por John Thornton ou Michael Gomez e a formulada por Ira Berlin ou Philip Morgan. Eu também insistiria, para o objetivo atual, em que essas versões rivais de tal narrativa-mestra da continuidade diferem significativamente - nos planos ideológico, metodológico e teórico. Mais adiante, tentarei sugerir como se poderia combinar o foco de Scott no discurso com um interesse pela história mais tradicional, a fim de gerar uma abordagem antropológica dos passados afro-americanos que seja a um tempo sólida, rigorosa e ideologicamente defensável.

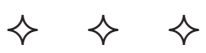

A Versão Número Um contemporânea da narrativa-mestra da continuidade é militantemente afrocêntrica, enfatizando o papel contínuo das etnicidades africanas nas Américas, e, muitas vezes, é explicitamente montada contra as teses do ensaio de M\&P. Tomo dois livros recentes como exemplos: o de Gomez, de 1998, e o de Thornton, de 1998a. Primeiro, porém, eu gostaria de preparar o terreno com alguns excertos de um texto mais programático de Paul Lovejoy (1997), que capta o sabor do discurso:

A perspectiva "afrocêntrica" supera uma deficiência fundamental na história dos africanos nas Américas, tal como analisada por muitos historiadores da escravatura, em particular os que se identificam com o modelo de "crioulização" desenvolvido por Sidney Mintz e Richard Price. [...] O foco proveniente da África implica que nem todos os escravos que foram para as Américas foram completamente desarraigados[,] como presume o modelo da "crioulização". [...] As implicações dessas suposições africanistas formam um nítido contraste com as da "escola da crioulização", que nega implicitamente a possibilidade de vínculos significativos contínuos, embora intermitentes, entre a África e a diáspora. [...] O modelo crioulo presume que a história africana não atravessou o Atlântico, porque a população escravizada tinha origens diversas demais para sustentar as continuidades da história. A disjunção é o conceito-chave. [...] Por causa desses antecedentes despersonalizados, só os "princípios culturais de nível profundo" sobreviveram à travessia do Atlântico. [...] [De acordo com o modelo da crioulização,] a crioulização resultou na rápida assimi- 
lação dos escravos africanos na "nova" cultura híbrida que evoluiu nas Américas. Ao rejeitar a preocupação de Herskovits com os "remanescentes", [...] Mintz e Price e seus protegidos subscrevem, na verdade, a visão de E. Franklin Frazier de que a cultura das Américas era "nova”. [...] Para os crioulistas, [...] "crioulo" significava, inevitavelmente, a "europeização" dos escravos oprimidos. [...] Eu diria que o conceito de crioulização, tal como costuma ser aplicado, é eurocêntrico, enfatizando o quanto a cultura africana foi subsumida e amalgamada, durante a escravidão, num molde "americano" que reforçou a dominação das pessoas de ascendência européia. [...] O processo de adaptação e invenção nas Américas, tal como entendido por Mintz-Price, pressupõe a destruição das culturas africanas. [...] A concentração nas Américas, que é explícita nas teorias da crioulização, efetivamente neutraliza a história africana. [...] A perspectiva das Américas, tal como concebida pela escola da crioulização, comumente faz uma representação equivocada da África e, a rigor, é anistórica. (Lovejoy, 1997:1, 2, 4, 6, 7, 16)

A meu ver, essa retórica "afrocêntrica" que está em voga hoje em dia ${ }^{5}$ serve, infelizmente, para polarizar e inflamar — pela criação de "escolas", pela insistência na visão superior dos africanistas e pelas distorções crassas do "modelo" de M\&P —, desviando estudiosos e alunos dos desafios propriamente históricos que nos confrontam.

A história que nos conta Michael Gomez em Exchanging our country marks: the transformation of African identities in the colonial and Antebellum South (1998) segue a tradição nacionalista cultural de Slave culture, de Sterling Stuckey (1987), porém modulada por um conhecimento muito mais pormenorizado da África. A grande afirmação do livro é que, "Do período colonial até o período que antecedeu a Guerra da Secessão, os africanos passaram aos poucos por um processo mediante o qual a base de seu autoconceito transferiu-se da etnicidade para a raça" (Gomez, 1998:242). Mas essa afirmação anódina é complementada por inúmeras historietas e exemplos, destinados a promover a hipótese de que determinadas etnicidades africanas desempenharam um papel mais determinante - e por um período muito mais longo - na vida dos escravos norte-americanos do que se supunha anteriormente. Para citar um exemplo típico, Gomez escreve que

Anna Miller, de Frogtown e Currytown, nos limites ocidentais do Savannah, também atestou, na década de 1930, que vários dos trabalhadores mais velhos da plantation de Butler Island falavam uma "língua engraçada". Tony William Delegal, que tinha mais de cem anos na época, sabia até cantar uma canção africana. [...]. O próprio fato de Delegal (uma forma de Senegal?) conseguir recordar a letra é um testemunho de que as 
línguas africanas foram mantidas vivas pelos nascidos na África e, em certas situações, transmitidas aos descendentes. ${ }^{6}$ (ibidem:174).

Tais historietas e exemplos são respaldados pelo que me parecem ser afirmações bastante infundadas (e, em geral, não historicizadas e não regionalizadas). Por exemplo,

Há indícios suficientes para demonstrar que muitos africanos, se não a maioria deles, continuaram a falar suas línguas nativas na América do Norte. [...] Não há comprovação sólida que corrobore a idéia popular de que os africanos recém-chegados de uma mesma etnicidade ou área de origem eram separados. Ao contrário, há todas as razôes para crer que eram mantidos juntos. [...] Na falta de informações capazes de corroborar as divisões intra-étnicas como um fenômeno geral, pode-se apenas postular a probabilidade de que os cativos vindos de uma mesma área fossem comprados e instalados juntos. [...] Em qualquer época anterior a 1830, é possível que $2 / 3$ a 3/4 de todos os escravos nascidos na África não soubessem falar ou não falassem um inglês ou francês reconhecíveis. Isso significa que ou falavam uns com os outros em suas línguas nativas, ou usavam uma versão tão africanizada do inglês/francês que ela era ininteligível para os brancos, ou ambas as coisas. [...] A retirada para o Maroon foi uma tentativa de recriar a África nos charcos e nos recônditos da América e, como tal, teria acarretado um certo grau de reafirmação da etnicidade. [...] Em 1720, portanto, a comunidade escrava [da América do Norte], para todos os fins práticos, era africana. [...] Durante todo o período colonial, a vasta maioria dos escravos nascidos na África e sua prole continuaram a praticar diversas religiōes africanas. [...] O desenvolvimento da sociedade africano-americana até 1830 foi, essencialmente, produto das contribuiçōes feitas por grupos étnicos [africanos] específicos. (ibidem: 172, 173, 180, 184, 194, 246 e 291)

Vale a pena notar que os desafios enfrentados pelos escravos, tal como Gomez os retrata, soam muito parecidos com os evocados por M\&P, por exemplo:

No decorrer da interação de africanos com africano-americanos, houve muitos dados a serem negociados. As preocupaçôes do dia-a-dia forneciam o arcabouço para grande parte do intercâmbio. As mulheres e homens dos dois lados do Atlântico discutiriam, necessariamente, quais eram as melhores maneiras de criar os filhos e instilar disciplina, o cuidado adequado com os idosos e enfermos, os melhores métodos de pesca e o que constituía uma conduta respeitável na presença dos mais velhos. [...] Ou seja, os negros tiveram que recriar sua sociedade, sua vida íntima coletiva, recorrendo a um sem-número de paradigmas étnicos e recebendo informaçóes da crise vigente. (ibidem:14-15)

Mas o entendimento de Gomez sobre como os escravos enfrentaram esses desafios difere radicalmente do modelo de M\&P, 
enfatizando sistematicamente a persistência de etnicidades africanas (quase essencializadas). Seus mapas detalhados da África ocidental e central, com os supostos destinos de várias etnicidades africanas na América do Norte, esquivam-se justamente das questôes que, a meu ver, os historiadores deveriam explorar com a mente mais aberta possível. Para mim, a organização do livro de Gomez - com capítulos centrais dedicados ao destino que tiveram nas Américas, primeiro, as pessoas provenientes do Senegâmbia e do golfo de Benin, depois, os africanos islâmicos, os serra-leoneses e acãs e, por último, os ibos e os africanos do Centro-Oeste africano - constitui uma hipótese que continua não comprovada e que, em muitos casos (alguns dos quais devem ficar claros pelas citações acima), contraria inteiramente os fatos. O ponto em que Gomez mostra o melhor de si, a meu ver, é na manutenção da ênfase na importância da hegemonia e da subjugação - e resistência -, ao explorar o desenvolvimento da cultura africano-americana e ao nos lembrar que, muitas vezes, os africano-americanos "engajavam-se mais em estilos de vida multiculturais do que sincréticos" ( $i b i-$ dem:10).

John Thornton, em Africa and Africans in the making of the Atlantic World, 1400-1800, reitera o apelo a uma perspectiva especificamente africanista sobre o desenrolar da etnicidade em lugares e períodos particulares nas Américas. Não obstante, seu material me parece muito mais convincente no que concerne à África - sobretudo o Centro-Oeste africano - do que às Américas. (Aliás, a primeira ediçãa de seu livro foi pioneira na demonstração do caráter disseminado e da importância da movimentação de pessoas e idéias, das trocas interculturais e de vários tipos de sincretismos e crioulizações - ora envolvendo os invasores e comerciantes europeus, ora não - dentro da própria África.) Ao se voltar para as Américas, entretanto, Thornton começa a escrever explicitamente contra o modelo de M\&P, afirmando que ele retrata "a mistura resultante" como "nitidamente européia e voltada para a Europa, com os componentes africanos a lhe dar mais sabor do que substância" (Thornton, 1992a:184). E, no tocante à questão crucial da heterogeneidade cultural dos africanos importados pelo Novo Mundo, embora assinale que, "de modo geral, as pesquisas modernas vêm tendendo a ladear com Mintz e Price, que afirmam ter havido grandes diferenças entre as culturas do litoral atlântico da África" (idem), Thornton procura mostrar que isso representa um exagero e que os africanos "nem de longe eram tão diversificados, a ponto de criar o tipo de confusão cultural postulada pelos que vêem a di- 
versidade africana como uma barreira ao desenvolvimento de uma cultura americana baseada na África” (ibidem:187). (É escusado dizer que nem Mintz nem Price jamais imaginaram ter havido uma "confusão cultural", tampouco qualquer deles jamais viu a diversidade como uma "barreira". Antes — e, neste ponto, falo explicitamente por mim - apresentei sistematicamente a diversidade cultural africana como um incentivo ao sincretismo e à crioulização inter-africanos.) Thornton afirma ainda que, nas grandes plantations das Américas, "os escravos, tipicamente, não tinham dificuldade de encontrar membros de sua própria nação com quem se comunicar" (ibidem:199), e que "o tráfico de escravos e a transferência subseqüente para as plantations do Novo Mundo, portanto, não foram um processo tão aleatório quanto o postulado pelos que afirmam que os africanos tiveram que partir do zero, em termos culturais, ao chegarem ao Novo Mundo" (ibidem:204). Eu gostaria de observar que a idéia de os afro-americanos haverem "partido do zero" não é uma posição endossada por ninguém há décadas, a despeito da afirmação de Lovejoy (citada acima) de que "Mintz e Price e seus protegidos subscrevem, na verdade, a visão de E. Franklin Frazier de que a cultura das Américas era 'nova'” .

$\mathrm{Na}$ versão do Panorama Geral fornecida por Thornton, a África impera triunfal, sistematicamente. Por exemplo, ele escreve que

Às vésperas da revolução de São Domingos, é muito provável que o quicongo também fosse a primeira língua mais comumente falada, ou seguisse muito de perto o francês. Na verdade, os líderes crioulos da revolução de 1791 queixavam-se de que a maioria de seus seguidores "mal conseguia entender duas palavras de francês" (ibidem:321).

Mas, de uma perspectiva americanista, seria útil assinalar que as opções de fala dessas pessoas não eram uma simples língua materna africana ou o francês. Aliás, em sua grande maioria, esses haitianos deviam falar uns com os outros em sua própria língua comum - nem o quicongo nem o francês, mas uma nova língua que eles (e as gerações de escravos africanos e seus descendentes que os precederam) haviam criado em São Domingos: o crioulo haitia no.

Eu gostaria de assinalar a tendência dos proponentes da postura afrocêntrica a desconhecer, sistematicamente, a massa de dados contrários que continuam a se acumular em todas as Américas (inclusive o trabalho feito por Sally e eu sobre a crioulização rápida do Suriname). Aguardei com grande expectativa a publicação da 
edição revista de Africa and Africans, de Thornton, cuja primeira edição havia parado em 1680 - ou seja, pouco antes da fundação das comunidades de quilombolas no Suriname. Como a segunda edição prometera atualizar os dados até 1800 , mandei que fosse despachada dos Estados Unidos para mim no Brasil, onde eu estava lecionando por um semestre. Mas, como dizem os franceses, Quelle déception! Nem uma palavra (ou sequer um erro tipográfico) foi modificada ou revisada nos dez primeiros capítulos. E o novo capítulo final sobre o século XVIII dedicou apenas um único parágrafo aos quilombolas do Suriname (cuja história primitiva e cujo desenvolvimento cultural estão hoje tão criteriosamente documentados, talvez, quanto os de qualquer sociedade da afro-América, e que, por si mesmos, constituem um poderoso exemplo contrário às generalizações de Thornton), e esse parágrafo baseou-se numa única fonte - um artigo de um professor holandês de Antropologia que nunca fez nenhum trabalho de campo entre os quilombolas.

Sem dúvida, esse tipo de apagamento deliberado dos conhecimentos contrários é tão lastimável quanto desnecessário. ${ }^{8} \mathrm{Os}$ dois campos professam compartilhar as mesmas metas intelectuais. É como se estivéssemos diante de um (pseudo) debate, baseado, até certo ponto, no carreirismo (numa rivalidade entre africanistas e americanistas e, vez por outra, entre historiadores e antropólogos), ou, o que é mais importante, nas ideologias ou partis pris subjacentes (que mal chegaram a ser reconhecidos e, com certeza, ainda não foram analisados por escrito). Como observou secamente Trouillot,

As teorias da crioulização ou das sociedades crioulas, as avaliações do que significa ser "crioulo", por sua vez, ainda são muito afetadas pela sensibilidade ideológica e política dos observadores. [...] Todos tomam a crioulização como uma totalidade, e portanto, distante demais das circunstâncias concretas enfrentadas pelos indivíduos engajados nesse processo. Todos esses modelos invocam a história. [...] No entanto, as condições históricas da produção cultural raramente se tornam uma parte fundamental e necessária das descrições ou análises geradas por esses modelos. Os apelos a um exame mais refinado das particularidades históricas [e, nesse ponto, o autor indica o ensaio de M\&P, numa nota de rodapé] continuam caindo em ouvidos moucos. (Trouillot, 1998:8-9) ${ }^{9}$

O ensaio de M\&P procurou, antes de mais nada, propor uma abordagem para o estudo do passado africano-americano (aliás, isso ficou explícito em seu título original: Uma abordagem antropológica do passado afro-americano). Para o estudo da escravi- 
dão nas Américas, ele tentou expor o tipo de constantes (por exemplo, as realidades das diferenças de poder) e o tipo de variáveis (por exemplo, demográficas, culturais, geográficas) que mereceriam a atenção dos estudiosos. Presumiu que, apesar de alguns traços comuns baseados nas relações de poder, a escravidão na Virgínia oitocentista, por exemplo, teria sido, em aspectos significativos, uma instituição diferente da escravidão no México seiscentista ou na São Domingos setecentista, e tentou apontar os tipos de processos que acarretariam essas diferenças. $\mathrm{O}$ toque de clarim do ensaio de M\&P consistiu na historicização e na contextualização - a mesma exploração criteriosa dos detalhes sócio-históricos a que Mintz conclamara, inicialmente, no estudo das línguas crioulas, na década de 1960 (Mintz, 1971). No entanto, ao expor sua tese, o ensaio de M\&P parece ter dado a alguns leitores a impressão de que os processos de crioulização relativamente serenos, rápidos e irreversíveis foram, necessariamente, a norma em todas as Américas. Ou seja, num ou noutro momento, ele pode ter ido mais longe do que pretendiam seus autores na sugestão de um modelo do "que realmente aconteceu” (em contraste com um modelo metodológico). E nisso, sugeriria eu, talvez parte da culpa tenha sido de minha própria experiência, então recente, com os saramacanos.

David Scott sugeriu que Herskovits e eu "descobrimos" nossos modelos de antropologia afro-americana entre os saramacanos (que assim, no dizer dele, tornaram-se "uma espécie de metonímia antropológica [...], proporcionando o campo exemplar em que defender certas afirmaçôes antropológicas sobre um domínio discursivo chamado afro-América" [1991:269]). E uma leitura recente dos diários de campo de Herskovits em Saramaca (Price \& Price, 2003b) confirmou a implicação de Scott de que, basicamente, Herskovits descobriu o que se dispusera a demonstrar (ver também Herskovits, 1969). No meu caso, porém, creio ter ficado sinceramente surpreso com (e despreparado para) a importância do discurso da "primeira vez" (de resistência à escravidão) encontrado na vida atual de Saramaca. Seja como for, na medida em que Scott sublinha que o antropólogo é produto de sua época e lugar e (será que me atrevo a dizê-lo?) de sua posição de sujeito, e que a África estivera tão no ar na Nova York do Renascimento do Harlem, na década de 1920, quanto a resistência (à escravatura e a outras opressões mais atuais) esteve no ar (assim como o gás lacrimogêneo) na Cambridge e na New Haven da década de 1960 (Bobby Seale e os Panteras estavam sendo julgados a poucos quarteirões de distância, no primeiro dia em que lecionei em Yale), não há dúvida 
de que ele captou alguma coisa. Enquanto colaborava no ensaio de $\mathrm{M} \& \mathrm{P}$, eu tinha muito presentes na lembrança as minhas experiências recentes com os saramacanos, e grande parte de minha contribuição para esse trabalho deve ter sido moldada por elas. E é bem possível que o fato de os ancestrais dos saramacanos modernos em virtude das especificidades de sua situação histórica — terem forjado sua sociedade mediante processos de crioulização mais rápidos e serenos do que os africanos que chegaram a outras partes das Américas tenha influenciado o esboço sumário que fornecemos. Por esta razão, é crucial separar o modelo metodológico, que creio ainda ter uma pertinência bastante geral, dos exemplos particulares que apresentamos (os quais, hoje em dia, poderiam ser muito expandidos, com base em tudo o que os estudiosos aprenderam nos 25 anos decorridos desde então). ${ }^{1}$

Como sugere Trouillot, devemos continuar a insistir nas particularidades históricas. ${ }^{11}$ E, quando Thornton e outros historiadores afrocêntricos passam do Panorama Geral (no qual as "preferências ideológicas" impulsionam sua narrativa) para "as circunstâncias concretas enfrentadas pelos indivíduos envolvidos no processo" de crioulização, é comum oferecerem percepções instigantes e levantarem problemas importantes para estudos adicionais. ${ }^{12}$ Por exemplo, as investigaçōes de Thornton sobre o papel dos escravos nascidos no Congo entre os participantes da Rebelião de Stono de 1739 (1991) e a Revolução Haitiana (1993) descortinam novas perspectivas intrigantes. ${ }^{13}$ Ao que parece, quanto mais específico (limitado no tempo e no espaço) é o estudo afrocêntrico dos fenômenos americanos, melhores são suas chances de ser historicamente persuasivo. Um artigo de Ray Kea, o historiador da Costa do Ouro, sobre uma revolta de escravos do século XVIII, nas Índias Ocidentais Holandesas, é um bom exemplo disso: ele consegue extrair com considerável sutileza, as conseqüências das origens "amina" dos escravos envolvidos, ajudando-nos a imaginar a mentalidade (ideologias, idéias sobre a autoridade, idéias sobre a morte) de pessoas que eram embarcadas num determinado porto, em determinada ocasião, em vista de determinadas circunstâncias locais da África, e a descrever um pouco como algumas delas se portaram num evento específico no Novo Mundo (Kea, 1992). Em suma, não há dúvida de que tal perspectiva africanista tem seu lugar em nosso instrumental para compreender os modos como os africanos escravizados e seus descendentes criaram comunidades e instituições em suas novas pátrias. Se usada a serviço de uma contextualização e historicização maiores, e não para promover um 
ataque generalizado e tendencioso à crioulização, tal perspectiva, embasada num rico conhecimento da história africana, não pode deixar de contribuir para nossa compreensão dos acontecimentos do lado de cá do Atlântico.

Voltando ao Panorama Geral - à narrativa mestra da continuidade —, poderíamos resumir a Versão Número Um como uma sucessora contemporânea, militantemente afrocêntrica, da narrativa dos remanescentes africanos criada por Herskovits nas décadas de 1920 e 1930 e aprimorada por Robert Farris Thompson nas de 1970 e 1980. Compatível com as posturas africano-americanas nacionalistas e culturais, ela enfatiza o poder de resistência das etnicidades africanas e esvazia os processos de crioulização ou miscigenação.

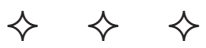

A Versão Número Dois, tal como expressa por historiadores norte-americanos contemporâneos, nasce do profundo conhecimento do Novo Mundo pelos estudiosos, em contraste com as realidades africanas, e portanto, é mais rica em sua textura histórica concernente à escravidão. É plenamente compatível com o projeto do ensaio de M\&P e com outros escritos mais ou menos contemporâneos, que frisaram a criatividade, a miscigenação e a crioulização do Novo Mundo, como os de Bastide (1978 [1960]), Joyner (1984) ou Levine (1977). Para nossos propósitos atuais, podemos considerar exemplares os trabalhos recentes de Ira Berlin e Philip Morgan. ${ }^{14}$ Em cada um deles, o ponto de partida é a comparação sistemática (entre regióes e ao longo do tempo), enquanto é destacada a complexidade do desenvolvimento cultural.

Berlin começa seu livro com a crença em que

Compreender que uma pessoa era escrava não é o fim da história, mas o começo, porque a história dos escravos derivou de experiências que diferiram de lugar para lugar e de época para época, e não de uma verdade trans-histórica imutável. [E, logo depois, ele generaliza a idéia de que] Em vez de partir do africano para o crioulo ou da escravidão para a liberdade, as pessoas de ascendência africana no continente norte-americano atravessaram muitas vezes a fronteira entre o africano e o crioulo e entre a escravidão e a liberdade, nem sempre no mesmo sentido. (Berlin, 1998:3 e 5)

O modelo de desenvolvimento da escravidão norte-americana usado por Berlin começa com a geração constitucional - os primeiros escravos não ligados aos navios, que não se en- 
quadram de modo algum nos estereótipos batidos dos africanos das travessias oceânicas. Na região de Chesapeake, por exemplo,

embora alguns recém-chegados proviessem diretamente da África, a maioria já havia passado algum tempo no Novo Mundo, entendia as línguas do Atlântico, tinha nomes hispânicos e, vez por outra, ingleses, e estava familiarizada com o cristianismo e outros aspectos da cultura européia. (ibidem:29)

Na Flórida, a geração constitucional equivalente de "crioulos do Atlântico" conseguiu sobreviver até o fím do século XVIII, ao passo que, nas terras alagadiças da Carolina do Sul, a geração constitucional foi tragada muito mais depressa pelos novos africanos importados para trabalhar nas grandes plantações de arroz que surgiram no fim do século XVII. Enquanto isso, afirma Berlin, a Louisiana assistiu a uma progressão diferente (de tipo mais caribenho), a uma transição mais serena e mais unidirecional do africano para o crioulo, bem como à transição de uma "sociedade escravocrata" para uma "sociedade com escravos" (ibidem:77). ${ }^{15}$ Grosso modo, na América do Norte de Berlin, a escravidão e a raça foram sendo constantemente construídas e reconstruídas conforme a mudança da situação histórica.

A descrição que Berlin faz da reafricanização dramática (e da recrioulização posterior) de Chesapeake contrasta com a imagem traçada por Gomez ou Thornton. Ao descrever como, no novo regime rigoroso do tabaco, "os escravos africanos e seus descendentes, às vezes aliando-se aos remanescentes das gerações constitucionais, começaram a reestruturar a vida negra", Berlin insiste em que, "Durante todo o período [de reafricanização], a maioria vinha de portos tão distantes entre si quanto Senegâmbia e Angola" (ibidem:114). E, depois de discutir de onde vinham os escravos, como chegavam e eram vendidos, e onde acabavam indo parar durante esse período de intensa reafricanização, ele resume: "Portanto, o tráfico de escravos na baía de Chesapeake funcionou no sentido de dispersar homens e mulheres de várias nações e reduzir a importância da nacionalidade africana" (ibidem:115). O "momento africano" terminou na quarta década do século XVIII, quando a vida em Chesapeake voltou a se transformar,

à medida que uma nova geração de africano-americanos obscureceu a maioria africana, pondo fim à era de dominação africana. [...] Chesapeake voltou a se tornar uma sociedade crioula. [...] O momento africano da história de Chesapeake foi passando, à medida que a população africana 
envelheceu e a geração ascendente de africano-americanos começou a se firmar. (ibidem:126-128)

Em suma, com respeito a essa região - e Berlin nos conduz por mudanças similares no tocante a outras partes da América do Norte - , temos uma imagem de imensa variação, na qual a etnicidade africana só desempenha um papel seletivo no tempo e no espaço, e na qual a crioulização - embora raramente discutida em termos explícitos nesse livro, que se concentra mais nos resultados do que no processo - é um motor sempre presente do desenvolvimento e da mudança.

O livro de Berlin deixa claro o quanto seria imprudente fundamentar um modelo geral do desenvolvimento da cultura dos escravos nas regiōes pantanosas da Carolina do Sul do início do século XVIII (onde, na bela frase de Thornton [1992a:320], "A cultura africana não estava sobrevivendo - estava chegando"), ou na baía de Chesapeake durante a era revolucionária, ou na Louisiana do começo do século XIX (ou, a propósito, na Saramaca dos séculos XVII e XVIII). As particularidades históricas são importantes, e a velocidade, o ritmo e a natureza da crioulização diferiram. Mas os pressupostos metodológicos e teóricos também têm importância. $\mathrm{O}$ modo como Berlin compreende a etnicidade (à semelhança de Morgan, ver adiante) me parece sensível e teoricamente fundamentado, e se aproxima muito mais do que é compartilhado pela maioria dos antropólogos do que a visão de Gomez, Thornton ou outros adeptos do afrocentrismo. Berlin assinala a ausência de uma idéia de "África" e a extrema flexibilidade das etnicidades na mente dos recém-escravizados:

A África abriga centenas, talvez milhares de "naçōes" diferentes. [...] A língua, a religião, a organização doméstica, a estética, a sensibilidade política e as tradiçôes militares transportadas pelos africanos do interior para as plantations não podem ser entendidas em seus aspectos gerais, mas apenas em suas particularidades, porque os povos escravizados não eram africanos, mas acãs, bambaras, fons, ibos ou mandeus. [...] As novas identidades [nas Américas] assumiram uma multiplicidade de formas. [...] A competição e a cooperação dentro de cada local agravaram os restos de antigas inimizades, conferindo à nacionalidade ou à etnicidade uma realidade sempre cambiante e, com isso, novos sentidos à identidade acã, bambara e fon. Nesse mundo mutável, a nacionalidade ou a etnicidade não se apoiavam numa solidariedade comunitária primordial, num atributo cultural nem na experiência comum, pois essas qualidades podiam ser adotadas ou descartadas à vontade. Nas Américas, os homens e mulheres identificados como angolas, ibos ou malês obtinham essas identidades, muitas vezes, não de sua terra natal de fato, nem do lugar de 
onde haviam desembarcado, mas por falarem, gesticularem e se comportarem como angolanos, ibos ou malês - ou se associarem com eles. [...] Para a maioria dos africanos, tal como para seus equivalentes brancos, a identidade era uma roupa que se podia vestir ou jogar fora. [...] A escolha, assim como a imposição ou o direito inato, determinavam quem seriam os recém-chegados. [...] Em suma, a formação da identidade dos escravos africanos não era automática nem irrefletida, uniforme nem unilinear. (Berlin, 1998:103-105)

Se o livro de Berlin pinta o Grande Quadro Comparativo da América do Norte, o livro igualmente ambicioso de Philip Morgan, Slave Counterpoint, concentra-se mais exclusivamente no desenvolvimento da cultura escrava em si. $^{17}$ Ao contrário do livro de Berlin, que se organiza segundo uma grade regional e cronológica, o de Morgan é organizado por instituições (vistas ao longo do tempo), examinando a vida material, o trabalho no campo, o trabalho especializado, as interações de brancos e negros, a vida familiar e assim por diante. Morgan sintetiza uma quantidade notável de dados, ao comparar o desenvolvimento cultural da região de Chesapeake e das terras pantanosas, a começar pelas informaçóes demográficas: os crioulos eram a maioria na Virgínia em 1720 (e, em 1780, 95\% dos escravos da Virgínia eram crioulos), enquanto, na Carolina do Sul, os africanos natos compuseram a maioria até meados do século, enquanto os crioulos formaram uma maioria de 2/3 em 1780 (Morgan, 1998:95). Morgan trata a etnicidade africana como importante, em certos momentos, mas como uma variável que desapareceu com relativa rapidez, em termos da política identitária dos escravos, tanto pela rápida crioulização quanto pelo aumento da consciência generalizada da raça no fim do século XVIII.

Na baía de Chesapeake, os crioulos eram maioria em quase todas as plantações e bairros no começo do século XVIII; eles deram o tom e forneceram o teor da vida escrava nessa região, desde época notavelmente precoce. Os africanos aprendiam com eles a entender do riscado. [...] As lições eram predominantemente transmitidas dos crioulos para os africanos. (ibidem:460-461).

Embora os desdobramentos na região pantanosa diferissem nos detalhes - "Em Charleston, até os escravos crioulos mais sofisticados viviam em estreita intimidade com os africanos" (ibidem:461) -, "a longo prazo, mesmo na região pantanosa, os africanos eram estrangeiros numa terra estranha” (ibidem:456). Em última instância, com efeito, Morgan vê a etnicidade e outros aspectos da cultura africana, sobretudo como "uma fonte a que [...] os es- 
cravos podiam recorrer" para forjar uma nova cultura africano-americana (ibidem:457). E sua discussão pormenorizada do desenvolvimento da religião dos escravos na América do Norte baseia-se, similarmente, em pressupostos como os de M\&P:

A religião dos escravos na América britânica setecentista destaca como os negros, trabalhando em condiçôes extremamente adversas e em meios radicalmente diferentes, conseguiram preservar alguns princípios profundos, extraídos de sua herança africana. Muita coisa se perdeu: poucos sacerdotes e quase nenhum ritual coletivo sobreviveram à travessia. [...] [Mas,] no nível fundamental das crenças epistemológicas, das relaçóes interpessoais e do comportamento expressivo, os escravos mantiveram viva uma parcela de seu "caráter" africano. Empenharam-se num processo de apropriação seletiva, ou improvisação estruturada, no qual os valores e práticas eram reinterpretados à medida que iam sendo incorporados. (ibidem:657-658) ${ }^{18}$

O fato de Morgan (assim como Berlin) recorrer a muitas das mesmas fontes (e, amiúde, às mesmas citações) de Gomez serve apenas para destacar o quanto são contrastantes as interpretações que eles dão ao "que realmente aconteceu". Morgan coloca os africanos "aprendendo o riscado" com os crioulos, enquanto Gomez vê os africano-americanos da segunda e até terceira gerações sendo "dominados" pelos da primeira geração e pelos africanos "natos". Numa das guinadas mais bizarras desse debate, um livro recente de Lorena Walsh, From Calabar to Carter's Grove: the history of a Virginia slave community (1997), parece ser lido quase como um teste de Rorschach pelos diversos participantes. Uma crítica no William \& Mary Quarterly declara que

a questão mais importante discutida por Walsh envolve as maneiras pelas quais os escravos africanos tornaram-se afro-virginianos, processos estes delineados no trabalho pioneiro dos antropólogos Sidney W. Mintz e Richard Price. O quadro fornecido por Walsh enquadra-se no modelo de crioulização desses autores, à medida que os novos escravos africanos e crioulos formaram uma cultura sincrética durante o século XVIII. [...] Historiadores das primeiras comunidades norte-americanas de escravos têm reavaliado o modelo de Mintz-Price, para compreender o surgimento de comunidades africano-americanas durante a escravatura. Alguns insistem em que, ao contrário do modelo, as primeiras comunidades de escravos preservaram culturas africanas etnicamente específicas. [...] O livro de Walsh sugere que, mesmo em condições que, pelos padróes da Virgínia, eram ideais para testar essa postura revisionista - Carter's Grove tinha muitos escravos que compartilhavam uma herança regional africana -, a crioulização avançou rapidamente. (Sidbury, 1998:631-633)

E Berlin extrai conclusões similares do livro de Walsh: 
Uma análise rigorosa do ambiente de uma única família de fazendeiros, durante mais de um século [Walsh, 1997], revela que, mesmo quando os escravos provinham de uma única área de coleta, as mudanças no tráfico negreiro ao longo do tempo, a chegada de pequenos grupos vindos de outras partes da África e a venda e a movimentação internas dos escravos impediam a transferência direta de qualquer nação ou cultura isolada para as Américas. (Berlin, 1998:410)

No entanto, a própria Walsh parece resistir a qualquer preço a essas conclusões. Numa sinopse recente do papel da etnicidade africana na América do Norte, apoiando-se maciçamente nos dados de seu livro, ela criticou Morgan - por afirmaçóes como

A tendência homogeneizadora de frisar a unidade cultural da África, de enfatizar o caráter não-aleatório do tráfico de escravos e de ver o predomínio de determinadas regióes ou etnicidades costeiras africanas na maioria dos ambientes americanos discorda das forças centrais que moldaram os primórdios do mundo Atlântico moderno (1997:142),

e enalteceu Gomez - por afirmações como "Uma discussão mais fundamentada do papel da etnicidade só pode elucidar melhor o exame da aculturação" (1998:9). É difícil escapar à conclusão de que a ideologia e a política - os traços específicos da política identitária norte-americana - continuam a nortear as narrativas-mestras, bem como a influir na maneira como elas são lidas (ver Mintz \& Price, 2003; Gates, 1998).

Talvez, como sugere Trouillot (1998:20), seja simplesmente cedo demais para fazer generalizações sobre a crioulização - "não refletimos o bastante sobre o que aconteceu em locais e épocas específicos para produzir um arcabouço que seja suficientemente sensível à época, ao lugar e ao poder". Mas os casos norte-americanos que examinamos aqui sugerem que talvez precisemos de mais do que maiores conhecimentos sobre os detalhes sócio-históricos. $\mathrm{Na}$ Antropologia, os casos clássicos de interpretações rivais implicam novos estudos (desde Redfield versus Lewis sobre Tepoztlan até Mead versus Freeman sobre Samoa), nos quais as mudanças decorrentes do intervalo de várias décadas de transformações in loco nem sempre são fáceis de distinguir das mudanças de paradigmas na disciplina, ou das diferenças decorrentes da habilidade e da personalidade dos etnógrafos. O que é marcante nos atuais debates norte-americanos sobre a escravidão é que temos estudiosos que escrevem ao mesmo tempo, usando praticamente os mesmos dados-e, muitas vezes, citando exatamente as mesmas fontes primárias -, e chegam a conclusões opostas. Talvez, no caso atual, os par- 
ticipantes simplesmente precisem continuar a brigar em público e em suas publicações, na esperança de que a Verdade e a Razão saiam vitoriosas...

Como alguém que, no rastro de Herskovits e Mintz, sempre defendeu uma visão pan-afro-americana, eu também advogaria aqui a necessidade de uma comparação mais ampla, tanto em toda a afro-América quanto através das disciplinas, como forma de empurrar esses debates para além de campos de batalha ideológicos particulares. (Os historiadores norte-americanos parecem ainda mais tacanhos nesses aspectos do que seus colegas do exterior.) Isso porque, com certeza, houve processos gerais similares de construção de culturas funcionando em toda parte. Para citar apenas dois exemplos do tipo de trabalho que ajudaria a trazer a paz para as multifacetadas guerras dos historiadores norte-americanos, há um livro erudito que passou recentemente por minha mesa, "Chi ma nkongo": Lengua y rito ancestrales en El Palenque de San Basilio (Colombia), no qual Armin Schwegler demonstra, primeiro, que as canções entoadas nos ritos aparentemente mais africanos dentre todos os palenqueros, os lumbalú, são (nas palavras de um crítico)

não o resultado parcialmente descreoulizado de canções originais africanas, mas criações essencialmente modernas [isto é, setecentistas ou oitocentistas], baseadas numa combinação do espanhol e do palenquero [a língua crioula local] regionais, às quais foram acrescentadas palavras e elementos onomatopaicos africanos e pseudo-africanos", e, segundo, "que a utilização ativa das línguas africanas faladas em Palenque desapareceu muito cedo, se é que, de fato, a população algum dia usou uma língua africana como meio principal de comunicação. (Lipski, 1998:357)

(Essa segunda idéia, sobre o desenvolvimento e a predominância precoces de uma língua crioula, é especialmente interessante, na medida em que Schwegler consegue mostrar que os africanos que fundaram Palenque caracterizavam-se por uma relativa homogeneidade lingüística, com as línguas bantas, particularmente o quicongo, fornecendo o substrato principal do novo crioulo.) Uma crítica recente desse livro chama-o de, "ao mesmo tempo, uma análise magistral da fugidia língua lumbalú e um grande avanço nos estudos afro-crioulos [...] um marco com o qual serão cotejados os futuros estudos das línguas e culturas crioulas" (ibidem:359-360).

Em linhas mais gerais, qual a melhor maneira de incentivarmos nossos alunos, assim como uns aos outros, a ler e reagir a tais trabalhos? No caso, trata-se de uma obra cara, em dois volumes, 
publicada na Alemanha, escrita em espanhol e concernente a uma comunidade negra do interior da Colômbia, mas é uma obra que tem lições cruciais a dar a cada um de nós que se interesse pelas questôes dos "africanismos" e da etnicidade africana nas Américas, seja em Tidewater, na Virgínia, ou na Bahia. Ou ainda, tive recentemente o privilégio de ler o manuscrito do estudo histórico de Randy Matory, Black Atlantic Religion: tradition, transnationalism and matriarchy in Afro-Brazilian candomble, que faz uma análise brilhante do papel ideológico da etnicidade africana e da criação e redefinição contínuas de etnicidades africanas na Bahia; ele será lançado proximamente pela Princeton University press (Matory, 2004). Minha convicção pessoal é que devemos seguir essas trilhas e dar continuidade ao trabalho de interpretação histórica, deixando para outros a assunção de posturas. Em minha opinião - que, nessa matéria, não mudou em nada desde o ensaio de $\mathrm{M} \& \mathrm{P}-$, a etnicidade africana continua a ser $u m$ (entre muitos) dos modos pelos quais os povos escravizados trazidos para o Novo Mundo pensaram (e, em algumas partes das Américas, continuam a pensar) neles mesmos, e desempenhou vários papéis em diferentes aspectos da vida, durante períodos variáveis e em diferentes locais do Novo Mundo. Talvez o resumo mais ponderado e atualizado dessa postura encontre-se num artigo de Philip Morgan (1997), no qual ele se pauta pelos dados mais recentes sobre o tráfico de escravos no Atlântico para examinar suas implicações culturais gerais para as sociedades do Novo Mundo. E, para obter materiais recentes e importantíssimos do lado africano, que dão um respaldo detalhado a essa postura, convém agora examinar o trabalho de David Northrup (2000, 2002).

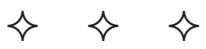

Como já foi assinalado, David Scott sugeriu uma reorientação da antropologia afro-americana para longe "dessa preocupação contínua [que ele encontra no trabalho de Herskovits e Price] com a corroboração ou a verificação de passados autênticos", deslocando-se para o "discurso" - "Entre aquele evento (a África ou a escravidão) e esta lembrança”, escreve ele, "estende-se um campo discursivo complexo, que é proveitoso chamarmos de 'tradição" (Scott, 1991:278). Tal como a entendo, a crítica radical de Scott negaria o objeto primário do estudo histórico - os passados que existem independentemente da imagem cultural que se faz deles. Mas não sou pós-modernista o bastante - nem tenho tanto medo 
de essencializar - para me dispor a descartar, digamos, as realidades da demografia setecentista, ou da legislação colonial, ou dos relatos das torturas praticadas para recuperar os escravos fugidos. Isso porque, segundo creio, todos elas têm efeitos, e não apenas no discurso ou na tradição, mas no presente. Proponho que abracemos os vestígios escritos, orais e de artefatos que nos foram deixados pelo passado, com todas as suas complexidades epistemológicas (e aceitando plenamente seu caráter construído), e façamos o melhor possível para re-apresentá-los com franqueza. Os saramacanos são mais do que "uma metonímia antropológica [...], proporcionando o campo exemplar em que defender certas afirmações antropológicas" (ibidem:269). Eles são, ao mesmo tempo, africano-americanos social e politicamente marginalizados, com tradições heróicas dos quilombolas, que, contrariando todas as expectativas, criaram uma cultura vibrante, e cuja vida (e estilo de vida) estão hoje tão ameaçados quanto estiveram em qualquer ocasião, desde o fim das guerras coloniais, há 250 anos. Sally e eu sentimos uma profunda responsabilidade, como antropólogos e amigos, por ajudar os saramacanos a contarem sua história, em parte como um meio de autodefesa contra a repressão severa e contínua (ver R. Price, 1995, 1998b; Price \& Price, 2001, 2003a).

O projeto de First-Time foi múltiplo, e nem todos os seus objetivos se encaixam harmoniosamente. Como qualquer trabalho ambicioso, ele tentou abordar diversas questões muito diferentes, que estavam no ar na época de sua redação. Um de seus alvos foram os historiadores céticos, esses tradicionalistas poderosos de todas as universidades que continuaram a negar a possibilidade de que os "povos primitivos" - particularmente os que não dispõem de uma escrita - pudessem ter um sentimento de seu passado que transcendesse o "mito". Meu livro, como o de meu colega de graduação e pós-graduação Renato Rosaldo sobre os ilongotes das Filipinas (1980), pretendeu, em parte, fazer um alerta aos historiadores (e a alguns antropólogos, inclusive Sahlins e Lévi-Strauss) sobre essa questão espinhosa. Um interesse correlato, de natureza mais decididamente herskovitsiana, foi demonstrar que esses africano-americanos, em particular, tinham realmente um passado projeto em que Scott está mais diretamente interessado. (Nesse ponto, o objetivo foi duplo - mostrar não apenas que entre os saramacanos havia historiadores que, a despeito das diferenças culturais, comportavam-se de modo muito semelhante aos nossos, mas também que sua visão coletiva do passado de Saramaca podia ser proveitosamente comparada com os registros mais tradicionais, 
construídos por não-saramacanos.) Um terceiro objetivo de First-Time foi puramente documental - apresentar e, com isso, preservar para a posteridade "a visão histórica" dos quilombolas saramacanos (generalizados no subtítulo do livro como "um povo afro-americano", a fim de tentar, se a memória tiver alguma serventia, apelar para um público maior do que o antropológico). ${ }^{19}$

Além desses interesses, First-Time procurou concentrar a atenção na dialética entre evento e memória, confiando em que os antropólogos afro-americanistas devem descobrir, em última instância, como analisar e representar os dois. Scott sugeriu que a "estratégia etnográfica ousada e inovadora" de First-Time só é plausível "na medida em que aceitemos a premissa conceitual de que o passado é passível de ser preservado e representado", e optou por "divergir do que parece ser a visão de Price, a saber, a de que o testemunho oral de seus informantes saramacanos e os textos escritos dos colonizadores holandeses são modos culturalmente diferentes, mas conceitualmente descomplicados, de representar o passado no presente" (R. Price, 1983a:67-68). Talvez por não ser do meu feitio exibir meus pressupostos teóricos em minha manga autoral, é provável que eu seja parcialmente responsável pelo entendimento equivocado que Scott tem de minhas idéias. Assim, eu gostaria de deixar registrado que First-Time parte da crença em que as verdades etnográficas e as verdades históricas são sempre verdades parciais - como Jim Clifford entendeu prontamente (1986)..$^{20} \mathrm{E}$ (mais uma vez, com o devido respeito a Scott) parto da suposição de que os testemunhos orais e os documentos de arquivo são imensamente complexos em termos conceituais. Por esse prisma, meu objetivo em First-Time não foi corroborar as lembranças contemporâneas saramacanas, usando arquivos do século XVIII, mas mostrar como (e, em muitos casos, por que) o discurso saramacano moderno, por um lado, e os documentos coloniais holandeses, por outro, constituem verdades parciais; ou seja, sempre procurei ter em mente as influências pertinentes, de natureza política, ideológica ou outra, na seleção, transmissão e silenciamento do passado - na produção da história - em cada um dos casos. Essa estratégia impõe graves desafios à representação, razão por que First-Time assumiu sua organização e diagramação inusitadas. E foi também por isso que não discuti mais longamente as consideraçôes políticas, ideológicas e outras que moldaram o discurso saramacano por mim apresentado no livro (embora tenha oferecido exemplos de como funcionam tais considerações) - ou seja, optei explicitamente por não sobrecarregar o leitor com nomes locais de pessoas e clãs 
e com a história pormenorizada das disputas políticas internas. Tampouco descrevi extensamente as questóes complexas da formação dos arquivos holandeses e outras fontes escritas, tema que abordei com mais detalhes num outro livro publicado no mesmo ano (1983b). De qualquer modo, minhas preocupações com a problematização das fontes orais, escritas e etnográficas estão sempre presentes em First-Time, creio eu, mas optei por não discorrer abertamente sobre elas, a fim de obter ao menos o nível de clareza de representação que consegui, ao apresentar realidades culturais muito estranhas e complexas a um público de língua inglesa.

Creio que, em vez de privilegiar o discurso, o que corre graves riscos, os afro-americanistas devem abraçar o discurso e o evento, descobrindo estratégias criativas de representação para lidar com os dois juntos. (Trouillot observou que, "À medida que a teoria social torna-se mais orientada para o discurso, a distância entre os dados e as afirmações nos debates sobre a crioulização [...] aumenta. As circunstâncias históricas caem ainda mais num confuso pano de fundo de preferências ideológicas" [1998:15].) Uma estratégia que usei largamente em First-Time consiste em ter as duas coisas em mente, mas tratá-las, alternadamente, como figura e fundo. Vários ensaios de Silencing the Past, de Trouillot (1995), constituem tentativas admiráveis de atingir objetivos similares com respeito ao Haiti do período revolucionário. Alabis World (1990) e, em especial, The Convict and the Colonel (1998a) constituem outras tentativas minhas de chegar aos mesmos fins, adotando estratégias diferentes de representação. No nível mais simples, afirmo que, para compreender plenamente o "discurso" (a memória coletiva e os modos pelos quais se atribui sentido a figuras como a escravidão, a resistência, ou a África da atualidade), devemos, simultaneamente, considerar o "evento" (a demografia - inclusive a etnicidade - ao longo do tempo, a sociologia e a economia de determinados regimes das plantations e assim por diante). E que, para compreender o "evento" ou a "história", devemos também considerar o "discurso" e a ideologia. Como poderíamos, por exemplo, sequer começar a compreender a importância (a monstruosidade) dos apagamentos e silenciamentos atuais do passado escravo, entre os camponeses e pescadores da Martinica, sem saber que, em certo sentido, Martinica foi a sociedade escravocrata por excelência - com 1/4 do tamanho de Long Island, mas recebendo aproximadamente o mesmo número de escravos africanos que a totalidade dos Estados Unidos (R. Price, 1998a)? Em suma, creio que nossa compreensão do passado africano-americano deve abar- 
car tanto a memória quanto o evento, se quisermos compreender qualquer um dos dois. E é por isso que (em meus escritos e aulas) os romances e a poesia ombreiam tão de perto com as monografias históricas e antropológicas. A história depende, em parte, da imaginação, assim como a memória coletiva depende, em parte, de eventos passados.

Sem dúvida, há diferenças geracionais subjacentes a parte do hiato entre a crítica de Scott e minha resposta. ${ }^{21}$ Em certo sentido, considerar o ensaio de M\&P ou First-Time como textos canônicos equivale a convertê-los em artefatos de um status quo pronto para ser ultrapassado. Dados os projetos novos e amiúde rivalizantes (ou até contraditórios) relacionados com suas respectivas problemáticas - e com todas as angústias concomitantes - no meio acadêmico moderno, não chega a surpreender que se estejam verbalizando críticas tão divergentes quanto as de Lovejoy e Scott. Apesar das continuidades nas realidades brutas do racismo norte-americano ao longo do tempo, o meio acadêmico passou por uma grande transformação nas três últimas décadas. A política da identidade, as questões da raça e do pós-colonialismo, o pós-modernismo e muitas outras coisas situam o jovem estudioso do fin-de-siècle num lugar muito diferente do antropólogo formado no fim do que George Stocking (1992) chamou de "período clássico" da disciplina (c. 1925-c.1965). Mas isso não impede o antropólogo de fazer novos truques. Se First-Time foi marcado por uma tensão entre o evento e o discurso - entre a tentativa de corroborar passados afro-americanos autênticos e a tentativa de desconstruir a produção da história - Enigma Variations, um romance recente escrito com Sally (Price \& Price, 1995), é marcado pela tensão entre a tentativa de seus protagonistas de avaliar a autenticidade de peças de "arte primitiva" e a tentativa dos autores de desconstruir a idéia de autenticidade. The convict and the colonel, que diz respeito a uma sociedade pós-colonial africano-americana bem diferente, toma o evento (a escravidão, o bagne), a memória (a minha, a deles) e o discurso (acadêmico, literário e "popular"), assim como a nostalgia, para examinar em linhas mais gerais de onde viemos e para onde podemos estar indo. Como constatou Stocking, é muito mais difícil historizar o presente extenso - o período iniciado na década de 1960, agora quase tão longo quanto o "período clássico" — do que o passado mais distante. Muitos dos interesses do meio acadêmico e da sociedade em geral, na época em que foram escritos o ensaio de M\&P ou First-Time, desapareceram, e um conjunto muito diverso de interesses assumiu seu lugar. As paixóes continu- 
am, seja sobre a etnicidade, seja sobre o discurso, mas foram radicalmente deslocadas.

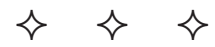

Por último, talvez num anticlímax, chegamos aos "princípios inconscientes" que Kevin Yelvington pediu-me para elucidar, quando me exortou pela primeira vez a redigir este ensaio. Nas palavras com que Trouillot hoje descreve o projeto,

Sidney Mintz e Richard Price sugerem que a herança cultural da África ocidental encontra-se principalmente em "princípios gramaticais [inconscientes e subjacentes]: orientaçōes cognitivas, atitudes, expectativas comuns às diversas comunidades de que provinha a maioria dos escravizados. Afirmam eles que esses princípios subjacentes ordenaram o processo de crioulização, tornando certas escolhas mais atraentes ou mais significativas do que outras opções possíveis. Essa tese precisa ser apurada, à luz de pesquisas mais contínuas sobre o impacto institucional da etnicidade africana nas práticas dos escravos de territórios específicos. Em outras palavras, os princípios subjacentes destacados por Mintz e Price tiveram que agir enfrentando as tensões entre os africanos, a fim de produzir práticas significativas, e precisamos saber como e quando o fizeram. E, mais importante, como quer que se tenha obtido um modus vivendi pautado pela gramática cultural entre os escravos, os princípios compartilhados - antigos e novos - tiveram que sobreviver ao exercício do poder europeu. Como o fizeram? Quando e como tiveram espaço e tempo para respirar e se desenvolver? Como sobreviveram e se reproduziram o bastante para gerar novas instituições? (Trouillot, 1998:21)

A idéia de princípios inconscientes num nível profundo, como chave para desvendar o passado africano-americano, é antiga (sobre a afirmação da "gramática da cultura", de Herskovits, ver Mintz \& Price, 1992:11). Grande parte do trabalho de Sally e meu poderia ser interpretada como uma tentativa de demonstrar o poder dessa idéia em campos específicos — desde uma visão geral dos padrões afro-americanos de denominação, escrita há quase três décadas (Price \& Price, 1972), até nosso livro recém-publicado, que discorre em detalhe sobre toda uma gama de campos estéticos (Price $\&$ Price, 1999). Das posturas ao vestuário, do bordado à costura de fitas, das esculturas em madeira às cabaças entalhadas, e da música e dança ao contar histórias, procuramos mostrar como princípios estéticos africanos amplamente compartilhados foram-se 
transmitindo ao longo de três séculos da história de Saramaca, partindo da demografia do tráfico de escravos e abrindo caminho através dos eventos e da memória, até chegar às técnicas de produção atuais. Uma vez que esse extenso livro está agora disponível para exame crítico e que a tese relativa aos "princípios inconscientes" foi exposta com certa minúcia (ver também o artigo de Sally nesta edição da $N W I G$ ), nem nossas descrições e análises da "crioulização no estilo saramacano" nem nossos relatos do complexo trabalho de campo envolvido no desvendamento desses "princípios inconscientes" precisam ser repisados ou reapresentados aqui. A prova, no que nos diz respeito, não deve estar em nossas afirmações, mas nos fatos.

Entretanto, vale a pena destacar o que esse livro - fruto de mais de três décadas de reflexão sobre o desenvolvimento da cultura saramacana - não diz (a rigor, não pode dizer) sobre a crioulização. Em última análise, os milagres dependem da fé, e o milagre da crioulização ainda não se mostrou uma exceção à regra. Berlin e Morgan, no tocante à América do Norte, ou Matory e os Prices, com respeito à América do Sul, fornecem uma farta contextualização dos processos de mudança cultural entre os recém-escravizados e seus descendentes no Novo Mundo. Quando essas obras atingem o que têm de melhor, é quase como se fôssemos testemunhas dos conflitos particulares, dos atos de solidariedade e imaginação envolvidos na passagem de um tipo de identidade para outro, ou de uma tradição do Mundo Antigo para uma nova tradição. No entanto, por mais que consigamos fazer retrocederem no tempo os primórdios desses desdobramentos culturais, vemo-nos presos na situação paradoxal, como Aquiles no paradoxo de Zenão, de nunca poder propriamente alcançar a tartaruga. Tal como os físicos, com seu nascimento do universo surgido da Grande Explosão [big bang], podemos teorizar o evento (ou o processo), mas nunca parecemos aptos a observá-lo de fato. Assim, o milagre supremo da crioulização permanece, ao menos por enquanto, impenetrável. Podemos imaginar (ou teorizar) como as mulheres e homens da plantation X elaboraram os procedimentos - os ritos, a música, as crenças - apropriados para o nascimento de gêmeos, a partir do momento em que a primeira mãe hipotética deu à luz seus bebês no Novo Mundo, mas jamais poderemos estar presentes nesse bendito evento em si. Sabemos que ele deve ter ocorrido e que, ao longo do tempo, aconteceu em dezenas de milhares de casos, quase sempre independentes, por toda a região das Américas. Um milagre que se repetiu interminavelmente. 
Com respeito a Saramaca, podemos agora fazer sua datação recuar em segurança para antes de meados do século XVIII: duas décadas de pesquisas arquivísticas desde o ensaio de M\&P permitem a demonstração inequívoca de que, em geral, naquela época, as etnicidades africanas não tinham destaque para os saramacanos, culturalmente, em termos da identificação de indivíduos ou como marcadores grupais. Em outras palavras, podemos demonstrar que a sociedade saramacana, na época do Tratado de Paz de 1762, estava muito mais próxima da Saramaca de hoje, em termos do desenvolvimento cultural, do que da África. No entanto, embora tenhamos podido fazer os grandes processos de crioulização retroceder ainda mais no tempo, continuamos impossibilitados de examiná-los diretamente.

Uma vez que nosso modelo antropológico da crioulização deriva da lingüística, talvez valha a pena uma última digressão, para examinar brevemente a situação atual entre nossos primos lingüistas. Mesmo numa disciplina que se orgulha de uma relativa sistematicidade e do método científico, a ideologia e as opiniões preconcebidas (e a posição do sujeito) parecem-me ser ao menos tão predominantes nela (e por motivos similares) quanto nas outras disciplinas relacionadas com os estudos afro-americanos. As teorias exclusivistas e monocausais da gênese das línguas crioulas quer baseadas na monogênese do pidgin português, nos substratos africanos, nos superestratos europeus ou na suposta programação biológica - parecem tão dominantes hoje quanto no passado. Um exemplo deve bastar. Num artigo recente de crítica sobre os crioulistas históricos, Derek Bickerton observou, em tom descontraído, mas contundente, que, "Como muitos (a maioria?) dos crioulistas francófonos, e ao contrário da maioria, se não de todos os crioulistas não-francófonos, Guy Hazaël-Massieux vê os crioulos como continuaçôes modificadas de seus superestratos" (1999:98). Não é notável — ainda que compreensível, dada a maneira como os franceses pensam em sua língua - que os crioulistas francófonos ainda insistam (a despeito de todas as provas coletadas por crioulistas não-francófonos), por exemplo, na primazia do francês na criação do haitiano ? $^{22} \mathrm{Ou}$ então, consideremos o veneno que Bickerton (idem) foi buscar para caracterizar a descrição de John McWhorter sobre a crioulização na costa oeste da África (1997), a qual, em suas palavras, é cheia de "meias verdades, inferências ilógicas e erros, [além de] simples falsificaçôes"; e ele acrescenta que "Para corroborar essa hipótese improvável em termos sociolingüísticos, McWhorter não é capaz de produzir uma única citação, um pingo 
de comprovação histórica”. Até uma simples espiada no Journal of Pidgin and Creole Languages mostraria que essa retórica bombásti$\mathrm{ca}$ (e interesseira) é quase a média em todos os lados do debate. $\mathrm{Na}$ medida em que os lingüistas crioulistas dependem dos historiadores, em última instância, para investigar o contexto sociocultural, e têm que inferir o processo efetivo de crioulização a partir de aspectos lingüísticos constatados a posteriori, na verdade eles se encontram em situação pouco melhor que a do resto de nós. Quer se trate dos Adãos e Evas saramacanos de Bickerton, na floresta tropical do Suriname, quer dos ancestrais dos saramacanos de McWorther, passeando por Coromantee, continuamos podendo apenas imaginar, usando todos os dados de que dispomos, um pouco de como deve ter sido.

E isso nos deixa, presumo, consideravelmente humilhados, com a tarefa de mais uma vez nos atirarmos em conjunto ao batente. No cômputo final, é só quando as narrativas rivais se confrontam e são cuidadosamente cotejadas que podemos começar a elaborar as razões para dar maior crédito a esta ou àquela. Não temos muita escolha senão continuar a lavrar os campos. No começo do século XXI, a "crioulização" - mesmo resistindo à observação direta - ainda continua a ser, na oportuna caracterização de Trouillot (1998:8), "um milagre que implora uma análise".

\section{NOTAS:}

1. Esse título inspirou-se, sem o menor pejo, na recente incursão de Michel-Rolph Trouillot no maravilhoso fenômeno da crioulização (1998, p. 8). Uma versão anterior deste artigo foi preparada para o Seminário Avançado "Da África para as Américas: Novas Direções na Antropologia Africano-americana”, da School of American Research, a ser publicado em Afro-Atlantic Dialogues: Anthropology in the Diaspora, organizado por Kevin A. Yelvington (Santa Fé, Novo México: SAR Press, 2004). Quero agradecer a Phil Morgan, Peter Redfield, David Scott e Rolph Trouillot, bem como aos integrantes do seminário da S.A.R. de 1999, por seus comentários generosos e úteis. Desde que este ensaio foi apresentado, reexaminei algumas questões constantes em R. Price, s/d. A tradução do inglês "The miracle of creolization: a retrospective" é de Vera Ribeiro.

2. Quero deixar claro desde já que, neste artigo, falo apenas em meu nome. Não discuti nenhum de seus aspectos com Mintz.

3. Escrevendo contra "os pressupostos ideológicos que servem para garantir a aparente autoridade dessas teses antropológicas concernentes [aos passados africano-americanos]", diz Scott (1991:268):

Esses pressupostos ideológicos têm a ver com o tipo de objeto antropológico em que se tem erigido, historicamente, o afro-americano ou o afro-caribenho (ou, 


\section{Richard Price}

enfim, o negro do Novo Mundo). Eu argumentaria que pelo menos um dos difundidos pressupostos ideológicos mediante os quais esse objeto teórico foi construído é que os povos de ascendência africana no Novo Mundo precisam de algo como a antropologia, uma ciência da cultura, para lhes fornecer a garantia fundamental de um passado autêntico.

4. Talvez valha a pena assinalar que, em contraste com a recente atenção dada por historiadores e antropólogos "de carteirinha" à história desses debates nos estudos africano-americanos, os estudiosos afro-americanistas da disciplina dos estudos culturais têm tendido a ignorar os debates dos últimos cinqüenta anos, com isso deixando o campo retoricamente livre para suas próprias "descobertas". Brackette Williams transmite essa idéia em sua crítica contundente de Black Atlantic, de Paul Gilroy (1993), quando conclama a atenção para seus silêncios. Nesse livro discutidíssimo, diz ela,

falta-nos uma ligação intelectual com os esforços do passado, para compreender processos de produção cultural que são produtos e produtores de unidades conceituais e embasadas, que são transculturais, pré-nacionais ou extranacionais [...]. Ficam silenciadas várias gerações de acadêmicos provenientes do Caribe e da América Latina e de estudiosos destes, cuja obra aborda as questôes levantadas por Gilroy ao longo de Black Atlantic. Com diferentes graus de sucesso, esses estudiosos de vários matizes procuraram compreender os processos de produção cultural e de formação da identidade em unidades conceituais que abarcam vários espaços geográficos e regimes econômicos superpostos (Williams, 1995:181, 188).

Depois, numa nota, ela deixa claro que está fazendo referência, entre outras obras, ao ensaio de M\&P. Num comentário à parte, Mintz opinou, de modo similar, que "O recente alvoroço sobre a modernidade caribenha e o Atlântico Negro é apenas a redescoberta da roda - C. L. R. James, entre outros, sabia disso há muito tempo" (1998, p. 128)

5. Lorena Walsh (1998:2) chega até a apontar - creio que com um exagero considerável - "uma ortodoxia emergente, que vê os escravos como formadores de comunidades identificáveis, baseadas em seu passado étnico ou nacional”.

6. Se essas historietas provam alguma coisa, poderíamos acrescentar que uma de minhas avós, nascida na Rússia, ensinou-me uma canção, e o avô sueco de Sally ensinou-lhe uma única frase - "Você gosta de pescar?" -, cada uma das quais constituiu as únicas palavras de sua língua materna que eles transmitiram diretamente, ou por meio dos filhos, a seus netos norte-americanos.

7. O uso sistemático que Thornton faz da expressão "a língua colonial” (que ele contrasta com várias línguas africanas), ao longo de seu novo capítulo sobre o século XVIII, denuncia seu parti pris. Em sua exposição, as línguas crioulas - que, na maioria dos territórios e em quase todas as épocas, eram o meio mais amplamente usado de comunicação entre os escravos - praticamente não existem.

8. Devo acrescentar que nada disso, ao que eu saiba, tem qualquer componente pessoal; os estudiosos que se opõem mal conhecem uns aos outros e não têm nenhum ressentimento particular de que eu tenha notícia - o que torna tudo isso ainda mais interessante, em termos intelectuais. 
9. Stephan Palmié (1997) fez observações similares sobre a má utilização ou a leitura equivocada do ensaio de M\&P:

Apesar de sua sofisticação teórica e sua solidez metodológica, o modelo da "rápida síntese inicial" sugerido por Mintz e Price não chegou a estimular uma historização rigorosa da antropologia africano-americana. Em vez disso, e contrariando as intençôes desses autores, às vezes ele parece haver estimulado a hipostasia do conceito de crioulização, numa medida tal que permite que se dissimule a história.

10. Na tentativa de seguir um provérbio saramacano - "Diz o lagarto: 'Velocidade é bom, mas cautela também é” - e com isso chegar a um certo equilíbrio, talvez eu esteja protestando demais nesse parágrafo. Dois leitores deste artigo - Phil Morgan e Rolph Trouillot -, embora concordando em que a força do ensaio de M\&P certamente é metodológica (uma "abordagem de"), exortaram-me (nas palavras de Trouillot) a "não abrir mão da importância central da questão da velocidade", ainda que, é claro, "deixando espaço para a descrioulização, a recrioulização ou outros processos, o que já é outra história", e (nas palavras de Morgan) a "me ater ao modelo primitivo da crioulização e não ceder muito terreno nesse campo [...]. Eu diria que a crioulização precoce aplica-se à maioria dos lugares".

Aqui talvez seja o lugar para reconhecer explicitamente a influência do falecido missionário e lingüista holandês Jan Voorhoeve na idéia de crioulização precoce usada no ensaio de M\&P, uma vez que surgiu recentemente uma grande reavaliação de sua obra (Meel, 1997).

11. Esse é, basicamente, o teor da visita mais recente que Sally e eu fizemos a essa questão geral, numa nota de rodapé de um livro recente (Price \& Price, 1999:329-330), onde observamos que

Monica Schuler criticou R. P. por enfatizar (exageradamente) a rapidez da crioulização e, em contraste, frisou o que ela percebe como a importância contínua da solidariedade étnica africana (Schuler, 1970, 1979, 1980; ver também Karasch, 1979). Alguns estudiosos afirmaram que os fazendeiros de certas colônias, em determinados momentos, incentivaram a manutenção da solidariedade étnica africana como um meio de controle, enquanto outros apontaram para a prática largamente comprovada de outros fazendeiros, no sentido de separar os escravos de determinadas origens étnicas com a mesma finalidade (para referências, ver $\mathrm{R}$. Price, 1979, p. 142). R. P. advertiu que "tais afirmaçôes, que se originam em dados provenientes de determinadas sociedades em determinados momentos históricos, só podem ser convertidos em generalizações com o risco de obscurecer a própria variação, que é crucial para se compreender a natureza da escravatura no Novo Mundo" (ibidem, p. 143).

Sugerimos, em seguida, que Roger Bastide, trabalhando com material brasileiro, abraçou uma visão que desfaz muitas dessas dificuldades. "Pouco sabemos sobre as religiōes afro-brasileiras naqueles tempos distantes", escreveu Bastide,

mas, com certeza, devemos abandonar a idéia de centros de culto [africanos] que tenham sobrevivido até hoje, durante séculos, (...) e pensar, antes, numa proliferação caótica de cultos ou fragmentos de culto, que surgiram apenas para morrer e dar lugar a outros, a cada nova onda de chegadas [africanas]. Os candomblés, xangôs e batuques de hoje não são remanescentes de antigas seitas que remontem ao passado brasileiro, e sim organizações relativamente recentes. (...) Assim, de- 


\section{Richard Price}

vemos pensar numa vida religiosa dos africanos que foi rompida e retomada, mas que, ainda assim, preservou de um século para outro (...) a mesma fidelidade à mística ou às místicas africanas. (Bastide, 1978 [1960]:47-48)

E a pesquisa recente de J. Lorand Matory (2004) sobre o candomblé da Bahia e a religião ioruba dá um respaldo considerável às afirmações de Bastide.

Por último, expressamos nossa simpatia pela crítica poética e imaginativa de Edward Kamau Brathwaite à tentativa de Monica Schuler de descrever o myal jamaicano como um remanescente solar do "Congo". "Talvez", escreve Brathwaite, "tenha sido assim na África central, mas, na Jamaica, ele foi (e é) um fragmento ou aspecto de uma forma crioulizada maior, que inclui o obiah, o jonkonnu e kuminalpukumina, ' convencer', o congo e o ettu" (1979:152 e passim).

12. Há uma bibliografia substancial de textos que enfatizam a contribuição cultural de etnicidades africanas específicas para tal ou qual colônia do Novo Mundo. Entre os mais interessantes, eu citaria Chambers (1996); Hall (1992); Karasch (1987); Littlefield (1981); Palmer (1995); Reis (1993); Schuler (1980); Walsh (1997).

13. Mais recentemente, Thornton (1998b) sugeriu a perspectiva africanista como uma estratégia de pesquisa mais geral, embora os dois estudos de caso por ele apresentados para respaldar essa idéia - um do Congo do início do século XVIII, outro do Daomé quase contemporâneo -, por mais ricos que sejam em sua textura africana, digam-nos pouco, afinal, sobre as conseqüências dos eventos africanos específicos para as comunidades do Novo Mundo em que desembarcaram os escravos expulsos. Anos atrás, escrevi uma longa crítica a uma abordagem do estudo do léxico saramacano que se centrava (casualmente) no Congo (R. Price, 1975), tentando sugerir alguns dos perigos existentes nela - perigos que não creio estarem inteiramente ausentes nem mesmo dos trabalhos afrocêntricos recentes e mais sofisticados.

14. Na época do seminário da S. A. R. (abril de 1999), esses dois livros tinham acabado de ser publicados. No fim do ano seguinte, já haviam acumulado, em conjunto, mais de uma dúzia de grandes prêmios literários.

15. Noutro contexto, eu poderia questionar algumas das trajetórias específicas postuladas por Berlin para suas diversas regiōes, como o baixo vale do Mississippi. Mas, apesar disso, sua ênfase geral na variação e no desenvolvimento não uniforme parece fundamental.

16. Num paralelo a essa postura, por uma perspectiva africana, Appiah escreveu com eloqüência sobre a natureza historicamente contingente das identidades étnicas — parte da razão por que a idéia de estabelecer uma "linha basal" africana para os estudos sobre o Novo Mundo foi tão repleta de problemas. Ele citou os comentários de Chinua Achebe sobre a relativa recenticidade da identidade "igbo" na Nigéria: "Por exemplo, tomemos o povo igbo. Em minha região, historicamente, eles não se viam como igbos. Viam-se como pessoas desta ou daquela aldeia. [...] No entanto, depois da experiência da Guerra de Biafra, durante um período de dois anos, essa se tornou uma consciência poderosíssima”. Em seguida, Appiah adverte que

Reconhecer a identidade igbo como uma coisa nova não é um modo de privilegiar outras identidades nigerianas: cada uma das três identidades étnicas centrais da vida política moderna - os haussá-fulanis, os iorubanoss e os igbos - foi produto da transição turbulenta do status colonial para o pós-colonial. David Laitin assinalou que "[a] idéia de que havia uma única tribo haussá-fulani [...] foi, basi- 
camente, uma alegação política do CPN [Congresso dos Povos do Norte] em sua batalha contra o Sul", ao passo que "muitos dos meus parentes mais velhos, intimamente envolvidos na sociedade iorubana rural de hoje, lembram que, ainda na década de 1930, 'iorubano' não era uma forma comum de identificação política”. [...] A Gana moderna assiste ao desenvolvimento de uma identidade akan, à medida que os falantes dos três principais dialetos regionais do twi - achânti, fante e akuapem - vão-se organizando numa corporação contrária a uma unidade ewe (igualmente nova). [...] As identidades são complexas e múltiplas, e brotam de uma história de respostas mutáveis às forças econômicas, políticas e culturais, quase sempre em oposição a outras identidades. (Appiah, 1992:177-178 [edição brasileira, p. 246-248])

17. Oriundo, em parte, do mesmo meio intelectual do ensaio de M\&P - o Programa de História e Cultura do Atlântico da Universidade Johns Hopkins, nas décadas de 1970 e 1980 -, o livro de Morgan poderia ser lido (embora, é claro, seja muito mais do que isso) como a implementação mais detalhada do projeto geral de M\&P já tentada em relação à América do Norte. Aliás, o texto usa uma linguagem de tipo notavelmente semelhante, ao discutir toda uma gama de questóes culturais, ao longo de suas mais de 700 páginas (ver, por exemplo, p. xxii, 257, 261, 442, 559, 580, passim).

18. Contrastem-se essas passagens com as seguintes, extraídas do livro de Gomez (e em parte já citadas acima): "Em 1720, portanto, a comunidade escrava [da América do Norte], para todos os fins práticos, era africana. O componente americano nato estava presente e continuou a crescer, de 1740 a 1760. [...] Entretanto, muitos destes eram americanos de primeira geração, de modo que se enquadrariam na proveniência de enculturação da ascendência africana. A combinação desses negros de primeira geração com uma população africana nata resultou em sua dominação dos africano-americanos de segunda e terceira geraçôes" (Gomez, 1998:194).

19. Numa leitura muito própria de sua época e lugar, Scott parece sugerir que o fato de os quilombolas saramacanos representarem, particularmente vistos pela perspectiva norte-americana, uma resposta relativamente nobre à escravidão, faz com que eles (e seus etnógrafos) pareçam um tanto suspeitos. Esse raciocínio entrosa-se com o "rebaixamento” da figura dos antes heróicos quilombolas (literários) pelo movimento martinicano contemporâneo da créolité (ver Price \& Price, 1999) e, ao que parece, faria parte de um movimento intelectual mais generalizado do Caribe pós-colonial.

20. "First-Time”, escreveu Clifford, "oferece um bom exemplo de parcialidade consciente e séria [...], uma prova de que a aguda consciência política e epistemológica não precisa levar ao ensimesmamento etnográfico nem à conclusão de que é impossível saber qualquer coisa ao certo sobre outras pessoas. Ela leva, antes, a uma idéia concreta de por que um conto popular saramacano, apresentado por Price, ensina que 'saber é poder, e que nunca se deve revelar tudo do que se sabe"” (Clifford, 1986:7).

21. Para mais informaçôes sobre o projeto de Scott de voltar a teorizar os horizontes da política pós-colonial, ver seu livro mais recente. Seu capítulo sobre a poesia de Kamau Brathwaite (Scott, 1999:106-127), no qual ele tenta "desvincular a visão de Brathwaite da epistemologia antropológica mediante a qual ele procura garanti-la" (ibidem:127), é particularmente pertinente às questôes abordadas neste artigo. 


\section{Richard Price}

22. Ver Price \& Price (1999), para uma discussão dos extremos anti-africanos (pró-franceses) a que os créolistes martinicanos levaram essas discussões sobre o desenvolvimento de sua língua natal.

\section{Referências Bibliográficas}

ALLEYNE, Mervyn (1988). Roots of Jamaican culture. London, Pluto Press.

APPIAH, Kwame Anthony (1997). In my father's house: Africa in the philosophy of culture. New York, Oxford University Press.

BASTIDE, Roger (1978 [1960]). The African religions of Brazil: toward a sociology of the interpenetration of civilizations. Baltimore, Johns Hopkins University Press.

BERLIN, Ira (1998). Many thousand gone: the first two centuries of slavery in North America. Cambridge, Mass., The Belknap Press/Harvard University Press.

BICKERTON, Derek (1999). "Perspectives on Creole language history". New West Indian Guide, n. 73, pp. 97-102.

BLASSINGAME, John W. (1972). The slave community: plantation life in the Antebellum South. New York, Oxford University Press.

BRATHWAITE, Edward Kamau (1979). "Commentary three". Historical Reflections, n. 6, pp. 150-155.

CHAMBERS, Douglas Brent (1996). "He Gwine Sing He Country": Africans, Afro-Virginians, and the development of slave culture in Virginia, 1690-1810. Tese de doutorado não publicada, University of Virginia.

CLIFFORD, James (1986). "Introduction". In James Clifford e George E. Marcus (orgs.), Writing culture: the poetics and politics of ethnology. Berkeley, University of California Press, pp. 1-26.

CROWLEY, Daniel J. (1981). Resenha de Afro-American arts of the Suriname rain forest, de S. \& R. Price. African Arts, n. 16, pp. 27, 80-81.

DILLARD, J. L. (1976). Black names. Haia, Mouton.

FRAZIER, E. Franklin (1939). The Negro family in the United States. Chicago, University of Chicago Press.

GATES, Henry Louis, Jr. (1998). "A call to protect academic integrity from politics". New York Times, sábado, 4 de abril, pp. A13, A15.

GENOVESE, Eugene D. (1974). Roll, Jordan, roll: the world the slaves made. New York, Pantheon.

GILROY, Paul (1993). The Black Atlantic: modernity and double consciousness. Cambridge, Mass., Harvard University Press.

GOMEZ, Michael A. (1998). Exchanging our country marks: the transformation of African identities in the colonial and Antebellum South. Chapel Hill, University of North Carolina Press.

HALL, Gwendolyn Midlo (1992). Africans in colonial Louisiana: the development of Afro-Creole culture in the Eighteenth Century. Baton Rouge, Louisiana State University Press.

HERSKOVITS, Frances S. (1969). "Introduction”. In Frances S. Herskovits (org.), The new world Negro, de Melville J. Herskovits. Bloomington, Minerva Press (orig. 1966), pp. vii-xi. 
JOYNER, Charles W. (1984). Down by the riverside: a South Carolina slave community. Urbana, University of Illinois Press.

KARASH, Mary (1987). Slave life in Rio de Janeiro, 1808-1850. Princeton, Princeton University Press.

_ (1979). "Commentary one". Historical Reflections, n. 6, pp. 138-141.

KEA, Ray (1992). "When I die, I shall return to my own land”: an 'Amina' slave rebellion in the Danish West Indies, 1733-1734”. In John Hunwick e Nancy Lawler (orgs.), The cloth of many colored silks: papers on history and society Ghanian and Islamic in honor of Ivor Wilks. Evanston, Illinois, Northwestern University Press, pp. 159-193.

LEVINE, Lawrence W. (1977). Black culture and Black consciousness: Afro-American folk thought from slavery to freedom. New York, Oxford University Press.

LIPSKI, John M. (1998). Resenha de “Chi ma nkongo”, de Armin J. Schwegler. New West Indian Guide, n. 72, pp. 356-360.

LITTLEFIELD, Daniel C. (1981). Rice and slaves: ethnicity and the slave trade in colonial South Carolina. Baton Rouge, Louisiana State University Press.

LOVEJOY, Paul E. (1997). "Identifying enslaved Africans: methodological and conceptual considerations in studying the African diaspora". Trabalho preparado para o UNESCO/SSHRCC Summer Institute, York University.

MATORY, J. Lorand (2004). Black Atlantic religion: tradition, transnationalism and matriarchy in Afro-Brazilian candomble. Princeton, Princeton University Press.

MCWHORTER, John H. (1997). Toward a new model of Creole genesis. New York, Peter Lang.

MEEL, Peter (org.) (1997). Opzoek naar Surinaamse normen: Nagelaten geschriften van Jan Voorhoeve (1950-1961). Utrecht, CLACS \& IBS.

MINTZ, Sidney W. (1988). "Routes to the Caribbean: an interview with Sidney W. Mintz (por Ashraf Ghani). Plantation Society in the Americas, n. 5, pp. 103-134.

_ (1971). "The socio-historical background to pidginization and creolization". In Dell Hymes (org.), Pidginization and creolization of languages. Cambridge, Cambridge University Press, pp. 481-496.

MINTZ, Sidney W. \& PRICE, Richard (2003). O nascimento da cultura africano-americana. Rio de Janeiro, Pallas.

MORGAN, Philip D. (1998). Slave counterpoint: Black culture in the Eighteenth-Century Chesapeake \& Lowcountry. Chapel Hill, University of North Carolina Press. (1997). "The Cultural Implications of the Atlantic Slave Trade: African Regional Origins, American Destinations and New World Developments", Slavery \& Abolition 18, 1997, p. 122-145.

NORTHRUP, David (2000). "Igbo and myth Igbo: culture and ethnicity in the Atlantic world, 1600-1850". Slavery \& Abolition, vol. 21, n. 2, pp. 1-20.

_ (2002). Africa's discovery of Europe, 1450-1850. New York, Oxford University Press.

PALMER, Colin A. (1995). "From Africa to the Americas: ethnicity in the early Black communities of the Americas". Journal of World History, n. 6, pp. 223-236.

PALMIÉ, Stephan (1997). "Ekpe/Abakua in middle passage". Trabalho apresentado na conferência sobre "Escravidão e Memória", Chicago.

PRICE, Richard (1998a). The convict and the colonel. Boston, Beacon Press. 


\section{Richard Price}

(1998b). "Scrapping Maroon History: Brazil's Promise, Suriname’s Shame”, New West Indian Guide 72, , p. 233-255.

_ (1995). "Executing ethnicity: the killings in Suriname". Cultural Anthropology, n. 10, pp. 437-471.

(1990). Alabi's world. Baltimore, Johns Hopkins University Press.

(1983a). First-Time: the historical vision of an Afro-American people. Baltimore, Johns Hopkins University Press (segunda edição, com novo prefácio do autor, Chicago: University of Chicago Press, 2002).

_ (1983b). To slay the Hydra: Dutch colonial perspectives on the Saramaka Wars. Ann Arbor, Karoma.

(1979). "Commentary Two". Historical Reflections, n. 6, pp. 141-149.

(1975). "KiKoongo and Saramaccan: a reappraisal". Bijdragen tot de Taal-, Land-en Volkenkunde, n. 131, pp. 461-478.

_ (s/d). "On creolization”. In David Eltis e Stanley L. Engerman (orgs.), Cambridge World History of Slavery. New York: Cambridge University Press.

PRICE, Richard \& PRICE, Sally (2003a). Les Marrons. Châteauneuf-le-Rouge, Vents d'Ailleurs.

_ (2003b). The root of roots: or, how Afro-American Anthropology got its start. Chicago, Prickly Paradigm Press/University of Chicago Press.

_ (2001). "Maroons under assault in Suriname and French Guiana". Cultural Survival Quarterly, vol. 25, n. 4, pp. 38-45.

(1999). "A política da identidade nas Antilhas Francesas". Estudos Afro-Asiáticos, n. 35, pp. 7-42.

(1999). Maroon arts: cultural vitality in the African diaspora. Boston, Beacon Press.

_ (1972). "Saramaka onomastics: an Afro-American naming system". Ethnology, n. 11, pp. 341-367.

RAWICK, George P. (1972). From sundown to sunup: the making of the Black community. Westport, Conn., Greenwood Press.

REIS, J. José (1993). Slave rebellion in Brazil: the Muslim uprising of 1835 in Bahia. Baltimore, Johns Hopkins University Press.

ROSALDO, Renato (1980). Ilongot headhunting, 1883-1974: a study in society and history. Stanford, Stanford University Press.

SCHULER, Monica (1970). "Akan slave revolts in the British Caribbean”. Savacou, n. 1, pp. 8-31.

_ (1979). "Afro-American slave culture". Historical Reflections, n. 6, pp. 121-137.

(1980). "Alas, Alas, Kongo": a social history of indentured African immigration into Jamaica, 1841-1865. Baltimore, Johns Hopkins University Press.

SCHWEGLER, Armin J. (1996). "Chi ma nkongo": Lengua y rito ancestrales en El Palenque de San Basilio (Colombia). Frankfurt, Vervuert.

SCOTT, David (1991). "That event, this memory: notes on the Anthropology of African diasporas in the new world". Diaspora, vol. 1, n. 3, pp. 261-284.

(1999). Refashioning futures: criticism after postcoloniality. Princeton, Princeton University Press.

SIDBURY, James (1998). Resenha de From Calabar to Carter's Grove, de Walsh. William \& Mary Quarterly, n. 55, pp. 631-633. 
STOCKING, George W., Jr. (1992). The ethnographer's magic and other essays in the history of Anthropology. Madison, University of Wisconsin Press.

STUCKEY, Sterling (1987). Slave culture: nationalist theory and the foundations of Black America. New York, Oxford University Press.

THORNTON, John (1991). "African dimensions of the Stono Rebellion". American Historical Review, n. 96, pp. 1101-1113.

(1992). "From the general to the particular: ethnicity and history in the slave trade". Trabalho apresentado na conferência "Transatlantic Slaving and the African Diaspora", Williamsburg, Virgínia, 11-13 de setembro.

(1992a). Africa and Africans in the making of the Atlantic World, 1400-1680. Cambridge, Cambridge University Press.

(1993). “I am the subject of the King of Congo': African ideology in the Haitian Revolution”. Journal of World History, n. 4, pp. 181-214.

TROUILLOT, Michel-Rolph (1995). Silencing the past: power and the production of history. Boston, Beacon Press.

(1998). "Culture on the edges: creolization in the plantation context". Plantation Society in the Americas, n. 5, pp. 8-28.

WALSH, Lorena S. (1997). From Calabar to Carter's grove: the history of a Virginia slave community. Charlottesville, University of Virginia Press.

(1998). "Ethnicity among Africans in North America". Trabalho apresentado na conferência "Transatlantic Slaving and the African Diaspora”. Williamsburg, Virgínia, 11-13 de setembro.

WILLIAMS, Brackette F. (1995). "Resenha de The Black Atlantic, de Paul Gilroy". Social Identities, n. 1, pp. 175-192. 